\title{
Opmerkelijk
}

\section{Autismespectrumstoornissen: van DSM-IV-TR naar DSM-5}

\author{
Jarymke Maljaars
}

\begin{abstract}
De DSM-5 is afgelopen mei op de markt gebracht. De komst van deze nieuwe editie van dit veelgebruikte diagnostisch handboek werd voorafgegaan door een reeks hoog oplaaiende discussies, onder meer door de nieuwe criteria voor autismespectrumstoornissen (ASS). Blijkbaar hebben niet alleen mensen met ASS weerstand tegen veranderingen, ook wetenschappers en clinici lijken het moeilijk te hebben met de overstap van de DSM-IV-TR naar de DSM-5. De veranderingen zijn dan ook niet gering.
\end{abstract}

\section{Subclassificaties of spectrum?}

Op basis van de DSM-5 kan enkel nog een classificatie autismespectrumstoornis worden gesteld. Aan studies die de afgelopen decennia probeerden om verschillende subgroepen binnen het autismespectrum te onderscheiden geen gebrek. $\mathrm{Er}$ is echter geen duidelijke evidentie dat diagnostisch onderscheid in de subclassificaties autistische stoornis (of kortweg autisme), stoornis van Asperger en PDD-NOS - zoals gedefinieerd in de DSM-IV-TR - ondersteunt. Onderzoeken die het gedrag van personen met Asperger en 'hoogfunctionerend autisme' vergelijken vinden veelal geen verschillen of tegenstrijdige resultaten (0.a. Ozonoff et al., 2000). In de klinische praktijk is gebleken dat de DSM-IV-TR criteria voor Asperger lastig toepasbaar zijn (Mayes et al., 2001). Het geheugen van ouders is vaak niet toereikend om de taalontwikkeling op jonge leeftijd retrospectief goed te kunnen beoordelen. Daarbij komt dat er sprake is van een voorrangsregel: de classificatie mag pas gegeven worden, wanneer niet voldaan is aan de criteria voor de autistische stoornis. Veel clinici hanteren dan ook een bepaalde mate van 'diagnostische vrijheid' bij het stellen van deze diagnose. Een ander probleem vormt de subclassificatie PDD-NOS. Hoewel het gaat om een restcategorie, blijkt dat deze classificatie zeer frequent wordt toegekend. Dat is zogezegd de wereld op zijn kop. Een spraakmakende Amerikaanse studie toonde aan dat de beste voorspeller voor het krijgen van een classificatie autisme, Asperger of PDD-NOS niet gelegen is in de gedragskenmerken, maar vooral te maken heeft met het centrum waar men heen gaat voor diagnostiek (Lord et al., 2012). Dit alles onderschrijft de eerste aanpassing in de DSM-5: de verschillende subclassificaties verdwijnen en alleen de overkoepelende classificatie ASS blijft over. Maar een classificatiesysteem blijft slechts een classificatiesysteem. Een dergelijke brede classificatie zal - ondanks de bijgevoegde ernstschaal - niet afdoende zijn om bijvoorbeeld handelingsgerichte adviezen te kunnen geven en is dus alleen bruikbaar wanneer deze vergezeld gaat van een geïndividualiseerd profiel van sterktes, kwetsbaarheden en noden.

\section{Triade of dyade?}

Velen zijn bekend met de huidige triade van problemen die bepalend zijn voor een ASS-classificatie in de DSM-IV-TR: (1) kwalitatieve tekortkomingen in sociale interactie, (2) kwalitatieve tekortkomingen in communicatie en (3) beperkte, repetitieve en stereotiepe patronen van gedrag, belangstelling en activiteiten. In de DSM-5 worden de eerste twee criteria samengevoegd tot: 
persistente tekortkomingen in sociale communicatie en sociale interactie over verschillende contexten heen. Sociale en communicatieve problemen zijn namelijk vaak onlosmakelijk met elkaar verbonden en daardoor lastig te onderscheiden. Uit verschillende factoranalytische studies blijkt dan ook dat een twee-factorstructuur gebaseerd op de DSM- 5 domeinen beter past dan een driefactorstructuur conform de DSM-IV-TR hoofdcriteria (o.a. Mandy et al., 2012). Binnen het sociaalcommunicatieve domein worden taalproblemen niet langer als een bepalende factor beschouwd voor een classificatie. De bijzonderheden in taal, zoals echolalie en idiosyncratisch taalgebruik, zijn toegevoegd als subcriterium onder de repetitieve en stereotiepe gedragingen. Binnen dit criterium is er in de DSM-5 eveneens aandacht voor hyper- ofwel hyporeactiviteit op bepaalde sensorische prikkels. Hiermee wordt recht gedaan aan de hoge frequentie van voorkomen van deze problemen en de vaak grote impact van deze gevoeligheden op het functioneren in het leven van alledag (Leekam et al., 2007).

\section{Nog meer veranderingen}

Er zijn nog diverse andere opmerkelijke veranderingen. Vanwege het feit dat bepaalde problemen pas tot uiting kunnen komen wanneer de sociale verwachtingen van de omgeving toenemen, zijn onder andere de regels rondom de aanvangsleeftijd versoepeld. Daarnaast verdwijnen verschillende exclusiecriteria. Zo zal een dubbele classificatie van bijvoorbeeld ASS en ADHD nu ook officieel mogelijk zijn; iets wat in de praktijk reeds veelvuldig gebeurde.

\section{Wie krijgt er nog een DSM-5 diagnose?}

Een veelgehoorde zorg rondom de aanpassingen in de DSM- 5 is: valt mijn kind straks buiten de boot? Voldoet iedereen die op basis van de DSM-IV(-TR) een ASS-diagnose heeft gekregen nog wel aan de nieuwe criteria? Een zeer terechte vraag. Met name hoger functionerende personen met een classificatie Asperger of PDD-NOS zouden op basis van de nieuwe criteria buiten het spectrum kunnen vallen. Naast de eerste studies die erop wezen dat de nieuwe criteria mogelijk strenger zouden zijn (o.a. Mattila et al., 2011; McPartland et al., 2012), zijn er nu ook onderzoeken die een positiever geluid laten horen (o.a. Frazier et al., 2012; Huerta et al., 2012; Kent et al., 2013). Al pleiten sommige van deze laatste onderzoeken wel voor een versoepeling van het aantal subcriteria waaraan moet worden voldaan binnen het sociaal-communicatieve domein. Deze onderzoeken zijn echter allemaal gebaseerd op retrospectieve data, verzameld aan de hand van diagnostische instrumenten die gestoeld zijn op de DSM-IV-TR. Deze instrumenten bestrijken echter vaak niet de volledige breedte van de nieuwe criteria, bijvoorbeeld omdat er geen items op het vlak van sensorische gevoeligheden zijn opgenomen. Dit neemt niet weg dat er wel een zekere verschuiving zichtbaar is: op basis van de DSM-IV-TR criteria kon iemand de classificatie PDD-NOS krijgen wanneer er sprake was van sociale en communicatieve beperkingen (criteria 1 en 2) zonder de aanwezigheid van stereotiep en repetitief gedrag (criterium 3). Dit is niet meer mogelijk op basis van de nieuwe editie. Vanwege de verbreding van het laatstgenoemde criterium wordt misschien alsnog aan de criteria voldaan. Indien dit niet het geval is, is er mogelijkerwijs een andere classificatie van toepassing: social (pragmatic) communication disorder, een nieuwkomer onder de noemer communicatieve stoornissen. De toevoeging van deze nieuwe stoornis zorgt echter ook weer voor veel onduidelijkheden en discussies. 


\section{Implementatie in de praktijk}

Naar schatting zal het nog wel even duren vooraleer de DSM-5 effectief geïmplementeerd zal worden in de klinische praktijk in Nederland en Vlaanderen. De Nederlandse Vereniging voor Psychiatrie adviseert om, in afwachting van gevalideerde vertalingen en de eerste ervaringen in de VS, pas tegen begin 2015 te starten met het gebruik van deze nieuwe editie. In Vlaanderen is er nog geen algemene richtlijn gesteld en zal op sommige plekken al eerder worden overgestapt op de nieuwe criteria. Aangezien goede individuele diagnostiek veel verder gaat dan alleen classificatie, verwacht men dat de invloed van de DSM-5 eerder beperkt zal blijven.

\section{Tot slot}

De prioriteiten bij deze revisie lagen bij de klinische bruikbaarheid en de onderzoeksmatige onderbouwing van keuzes. De discussies hebben al veel teweeg gebracht in de wereld van het autismeonderzoek. Alleen de tijd zal ons leren of de veranderingen, ook in de diagnostische praktijk, een verbetering vormen. Laten we de DSM- 5 daarom verwelkomen met een gezonde kritische blik! Er blijft tenslotte altijd ruimte voor verbetering. De nieuwe editie wordt niet voor niets aangeduid met een Arabisch cijfer wat de nummering voor tussentijdse edities vereenvoudigt. De bedoeling is dan ook dat, zodra nodig, revisies per sectie kunnen worden uitgebracht.

Dr. Jarymke Maljaars is postdoc-onderzoeker bij de onderzoekseenheid Gezins- en Orthopedagogiek aan de KU Leuven.

\section{Referenties}

Frazier, T. W., Youngstrom, E. A., Speer, L., Embacher, R., Law, P., Constantino, J., ... Eng, C. (2012). Validation of proposed DSM-5 criteria for autism spectrum disorder. Journal of the American Academy of Child and Adolescent Psychiatry, 51, 28-40.

Heurta, M., Bishop, S. L., Duncan, A., Hus, V., \& Lord, C. (2012). Application of DSM-5 criteria for autism spectrum disorder to three samples of children with DSM-IV diagnoses of pervasive developmental disorders. American Journal of Psychiatry, 169, 1056-1064.

Kent, R., Carrington, S., Le Couteur, A., Gould, J., Wing, L., Maljaars, J., ... Leekam, S. (2013). Diagnosing autism spectrum disorder: Who will get a DSM-5 diagnosis? Journal of Child Psychology and Psychiatry. doi:10.1111/jcpp.12085.

Leekam, S. R., Nieto, C., Libby, S. J., Wing, L., \& Gould, J. (2007). Describing the sensory abnormalities of children and adults with autism. Journal of Autism and Developmental Disorders, 37, 894-910.

Lord, C., Petkova, E., Hus, V., Gan, W., Lu, F., Martin, D. M., ... Risi, S. (2012). A multisite study of the clinical diagnosis of different autism spectrum disorders. Archive Gen Psychiatry, 69, 306-313.

Mandy, W. P. L., Charman, T., \& Skuse, D. H. (2012). Testing the construct validity of proposed criteria for DSM-5 autism spectrum disorder. Journal of the American Academy of Child and Adolescent Psychiatry, 51, 41-50.

Mattila, M. L., Kielinen, M., Linna, S. L., Jussila, K., Ebeling, H., Bloigu, R., ... Moilanen, I. (2011). Autism spectrum disorders according to DSM-IV-TR and comparison with DSM- 5 draft criteria: An epidemiological study. Journal of the American Academy of Child and Adolescent Psychiatry, 50, 583-592.

Mayes, S. D., Calhoun, S. L., \& Crites, D. L. (2001). Does DSM-IV Asperger's disorder exist? Journal of Abnormal Child Psychology, 29, 263-271.

McPartland, J. C., Reichow, B., \& Volkmar, F. R. (2012). Sensitivity and specificity of proposed DSM-5 diagnostic criteria for autism spectrum disorder. Journal of the American Academy of Child and Adolescent Psychiatry, 51, 368-383.

Ozonoff, S., South, M., \& Miller, J. N. (2000). DSM-IV-defined Asperger syndrome: Cognitive, behavioral and early history differentiation from high-functioning autism. Autism, 4, $29-46$. 